\title{
Clinical application of new technique that measures C4d for assessment of activation of classical complement pathway
}

\author{
E T DAVIES, B A NASARUDDIN, A ALHAQ, G SENALDI, D VERGANI \\ From the Department of Immunology, King's College School of Medicine and Dentistry, London
}

SUMMARY A new laser nephelometric technique that measures C4d for the assessment of the activation of the classical complement pathway was developed. C4d was isolated from other larger C4 related molecules at a final concentration of polyethylene glycol of $12 \%$ and then quantitated by laser nephelometry using a commercially available antiserum, which reacts with $\mathrm{C} 4 \mathrm{~d}$ determinants. $\mathrm{C} 4 \mathrm{~d}$ standard $(100 \%)$ was produced by exhaustive activation of the classical pathway in pooled normal human serum using heat aggregated human immunoglobulin. Serial dilutions of the standard provided a reference curve against which clinical samples were read. Patients with rheumatoid arthritis showed significantly higher $\mathrm{C} 4 \mathrm{~d}$ values (mean $53.8 \%)$ than controls $(21.7 \% ; \mathrm{p}<0.001)$. The technique proved accurate, rapid, and suitable for the routine laboratory evaluation of complement activation through the classical pathway, and it may be useful in the management of those conditions in which complement activation has a pathogenic role.

A common feature of connective tissue disorders is tissue damage caused by activation of the complement system.' Detection and quantitation of complement activation may be useful for monitoring disease activity. $^{2}$

The laboratory assessment of complement activation is usually based on the circulating concentrations of $\mathrm{C} 3$ and $\mathrm{C} 4{ }^{3}$ Values below the normal range are assumed to be due to consumption; but such an assumption can be misleading when used as an assessment of complement activation. Variations in the concentrations of complement factors can occur for reasons other than consumption. In rheumatoid arthritis and in the seronegative arthritides both $\mathrm{C} 3$ and $\mathrm{C} 4$ serum concentrations are often increased due to their behaviour as acute phase reactants. ${ }^{4}$ Conversely, the low concentrations of $\mathrm{C} 4$ in systemic lupus erythematosus may be genetically determined due to the possession of null $\mathrm{C} 4$ allotypes.

Complement activation can be incontrovertibly shown by measuring complement fragments, which are generated during complement activation. ${ }^{3}$ A nephelometric technique for the determination of the fragment $\mathrm{C} 3 \mathrm{~d}$ in plasma, following its isolation in polyethylene glycol (PEG), has recently been des-

Accepted for publication 18 August 1987 cribed. ${ }^{6}$ Raised C3d concentrations, however, do not indicate the activation route, as both classicial and alternative complement pathways converge at $\mathrm{C} 3$ level with production of $\mathrm{C} 3 \mathrm{~d}$ (fig 1 ). ${ }^{7} \mathrm{C} 4 \mathrm{~d}$ is a low molecular weight (44 500) fragment cleaved from C4 during activation of the classical complement pathway (figs 1 and 2). ${ }^{8}$ Its measurement may therefore provide an estimation of the classical pathway activation.

We report a nephelometric technique for the quan-

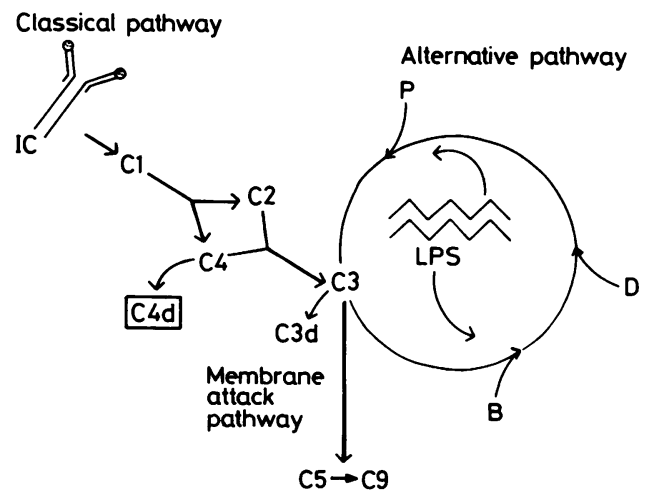

Fig 1 Diagram of complement pathways. Activation of both classical and the alternative pathway leads to splitting of $C 3$ with production of $C 3 d$. IC = Immune complexes. $L P S=$ lipopolysaccharides. 


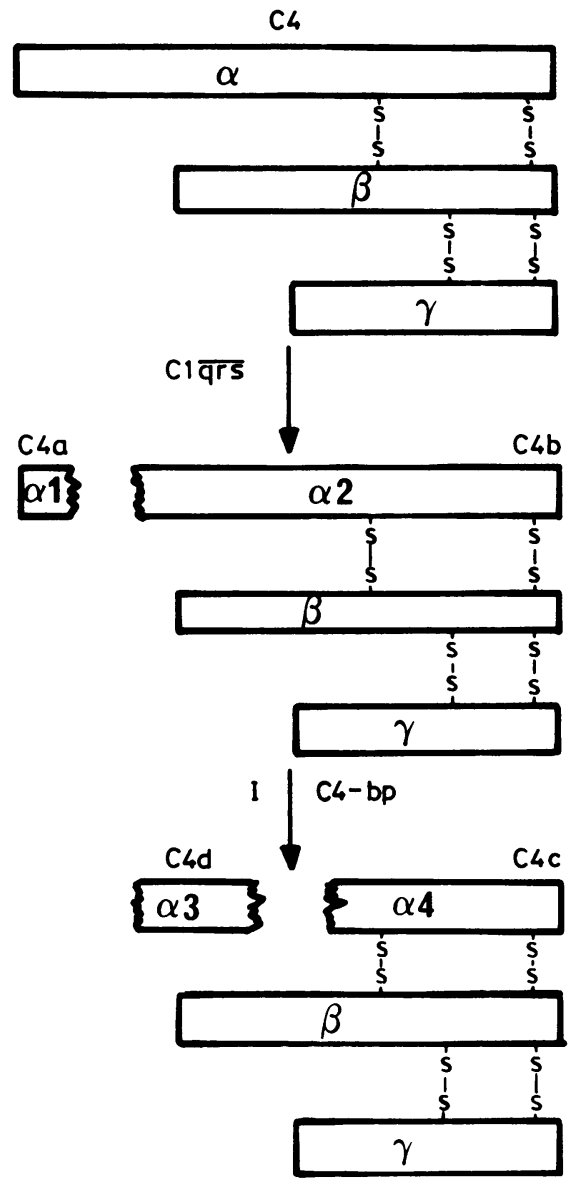

Fig 2 Schematic representation of cleavage of C4.

titation of $\mathrm{C} 4 \mathrm{~d}$ in plasma. The clinical relevance of the assay was investigated by determining $\mathrm{C} 4 \mathrm{~d}$ concentrations in healthy subjects and in patients with rheumatoid arthritis, where activation of the classical complement pathway is known to occur. ${ }^{910}$

\section{Material and methods}

Twenty healthy subjects (nine men, median age 31 , range $22-53$ ) and 50 patients ( 10 men, median age 48 , range 16-72) with classical or definite rheumatoid arthritis, defined according to the criteria of the American Rheumatism Association, were studied. Blood collected into a final concentration of $10 \mathrm{mmol} / 1$ edetic acid was immediately centrifuged at $1000 \mathrm{~g}$ at $4^{\circ} \mathrm{C}$ for 15 minutes; the plasma was separated and stored at $-70^{\circ} \mathrm{C}$.

\section{C4d STANDARD}

A pool of normal human sera was incubated at $37^{\circ} \mathrm{C}$ for 60 minutes with $5 \mathrm{mg} / \mathrm{ml}$ of heat aggregated human immunoglobulin (HAGG), which exhaustively activates the classical pathway. "HAGG was prepared by heating a purified Cohn fraction II (Sigma Chemicals, Poole, Dorset) at $63^{\circ} \mathrm{C}$ for 20 minutes. ${ }^{12}$ After centrifugation of the activated serum at $1500 \mathrm{~g}$ for 30 minutes the $\mathrm{C} 4 \mathrm{~d}$ rich supernatant was recovered, aliquoted, and stored at $-70^{\circ} \mathrm{C}$. This preparation was used throughout the study as the source of C4d standard.

\section{PEG ISOLATION OF C4d}

To isolate $\mathrm{C} 4 \mathrm{~d}$ from native $\mathrm{C} 4$ and the larger $\mathrm{C} 4$ fragments $100 \mu \mathrm{l}$ of $\mathrm{C} 4 \mathrm{~d}$ standard were added to $100 \mu \mathrm{l}$ of PEG 6000 (Sigma Chemicals) in borate buffer saline (BBS), pH 8.3, $0.1 \mathrm{~mol} / 1$, to achieve final concentrations ranging between $6-18 \%$. After incubation at $4^{\circ} \mathrm{C}$ for 90 minutes these preparations were spun down at $1500 \mathrm{~g}$ at $4^{\circ} \mathrm{C}$ for 30 minutes and the supernatants recovered. The efficacy of various PEG concentrations in separating C4d was assessed by immunoelectrophoresis performed in $1.2 \%$ agarose 15 (BDH Biochemicals, Poole, Dorset) in barbitone buffer, pH 8.6, $45 \mathrm{mmol} / \mathrm{l}$, at $10 \mathrm{~V} / \mathrm{cm}$ for 60 minutes. Optimal PEG concentration was considered to be that removing any slow migrating $\mathrm{C} 4$ moiety, but leaving in solution a fragment migrating in the alpha region (C4d). ${ }^{12}$

\section{SELECTION OF ANTISERUM}

As no specific anti-C4d antiserum is commercialiy available, several anti-C4 antisera were tested for their ability to detect $\mathrm{C} 4 \mathrm{~d}$. These included anti-C4 antisera from: Atlantic Antibodies (American Hospital Supply, Compton, Berkshire); Dakopatts (Dakopatts, High Wycombe, Buckinghamshire); Kallestad (Kallestad Laboratories, Brill, Buckinghamshire); Immuno (Immuno Diagnostics, Sevenoaks, Kent); Northeast (Northeast Biomedical Laboratories, Uxbridge, Middlesex); Pel-Freez (Pel-Freez Clinical Systems, Uxbridge, Middlesex); and Seward (Seward Laboratories, London). Two further antisera by Behring (Behring Diagnostics, Hounslow, Middlesex) were also tested-anti-C4 laser nephelometry grade antiserum and anti-C4 intact antiserum. An antiserum was considered to be reactive with $\mathrm{C} 4 \mathrm{~d}$ if capable of forming a precipitin arc in the alpha region, when tested by immunoelectrophoresis against a preparation containing fragments derived from the cleavage of C4 (C4d standard).

\section{MEASUREMENT OF C4d BY}

\section{LASER NEPHELOMETRY}

To define the optimal conditions of the assay a checker board titration was performed. supernatant 


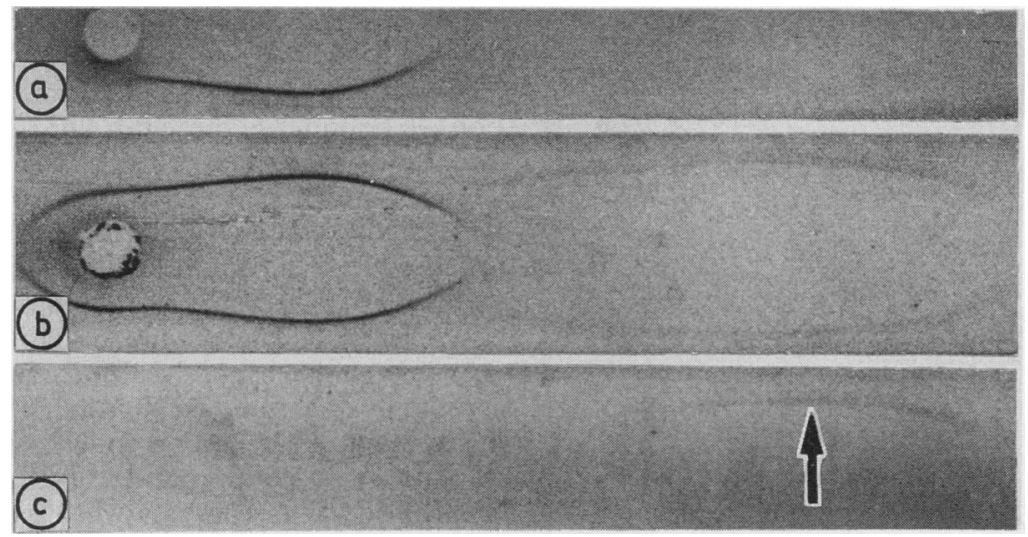

Fig 3 Immunoelectrophoresis of $C 4$ and its split products. Well a: normal edetic acid plasma; well $b C 4 d$ standard (pooled normal human serum activated by heat aggregated human immunogobulin); well c supernatant recovered after PEG treatment of C4d standard at a final concentration of $12 \%$; troughs anti-C4 intact antiserum by Behring. Anti-C4 antiserum reacts with alpha migrating fragment contained in $C 4 d$ standard $(b)$ which is still present (arrow) after PEG treatment $(c)$, while slower $C 4$ related molecules are successfully removed by treatment with PEG at a final concentration of $12 \%$ (c). No alpha migrating fragment can be detected in normal edetic acid plasma (a) where only intact $C 4$ is identified.

from PEG treated C4d standard was serially diluted in BBS and incubated at room temperature with different dilutions in BBS of the anti-C4 antiserum. Readings were taken in a Behring laser nephelometer at 30,60, 90,120 , and 180 minutes and compared with a reference curve prepared from $\mathrm{C} 4 \mathrm{~d}$ standard.

Clinical data are presented as mean $\pm 2 \mathrm{SD}$. The difference between mean values was evaluated using Student's $t$ test.

\section{Results}

\section{PEG ISOLATION OF C4d AND ANTISERUM SELECTION}

A final concentration of PEG of $12 \%$ separated C4d from larger $\mathrm{C} 4$ related molecules (fig 3). At this concentration of PEG larger $\mathrm{C} 4$ molecules were completely removed by centrifugation and the smaller $\mathrm{C} 4 \mathrm{~d}$ remained in the supernantant. Higher PEG concentrations also tended to precipitate $\mathrm{C} 4 \mathrm{~d}$. The antiserum best able to detect $\mathrm{C} 4 \mathrm{~d}$ was anti-C4 intact antiserum (Behring Diagnostics), which gave a distinct precipitin line in the alpha region (fig 3 ). This antiserum was therefore used for the study.

\section{MEASUREMENT OF C4d BY LASER NEPHELOMETRY} The optimal conditions for the measurement of $\mathrm{C} 4 \mathrm{~d}$ by laser nephelometry were as follows. After isolation of $\mathrm{C} 4 \mathrm{~d}$ by precipitation at $12 \%$ PEG supernatants from test samples were diluted $1 / 2.5$ in BBS and added to an equal volume of anti-C4 antiserum diluted $1 / 5$ in BBS. The final PEG concentration was thus reduced to
$2 \cdot 4 \%$. The top point of the reference curve was obtained by diluting the supernatant of the C4d standard (containing $12 \%$ PEG) $1 / 2.5$ in BBS. This first dilution leads to a PEG concentration of $4.8 \%$. The remaining points of the reference curve were derived by double dilution of the top standard to $1 / 80$ in $4.8 \%$ PEG in BBS (fig 4). The addition of $1 / 5$ antiserum to all the supernatant dilutions brought the final PEG concentration to $2 \cdot 4 \%$. This detail is important as PEG influences the kinetics of immunoprecipitation reactions. ${ }^{14} \mathrm{C} 4 \mathrm{~d} /$ anti-C4d reaction was read in the nephelometer after 90 minutes' incubation.

C4d could also be measured under different experimental conditions. Final concentrations of PEG between $2.0 \%$ and $3.0 \%$ were found to be suitable for the performance of the assay; higher and lower concentrations decreased its sensitivity. The final PEG concentration of $2.4 \%$ was adopted as it offered the best discrimination between small changes of $\mathrm{C} 4 \mathrm{~d}$ concentration. For similar sensitivity reasons the dilution of the anti-C4 antiserum chosen was $1 / 5$. The nephelometric readings of $\mathrm{C} 4 \mathrm{~d} / \mathrm{anti}-\mathrm{C} 4 \mathrm{~d}$ reaction became stable at 90 minutes, remaining stable thereafter. Ninety minutes, therefore, was chosen as the optimal period of incubation.

The intra-assay coefficient of variation derived from determining the same sample 30 times was $6.0 \%$. The interassay coefficient of variation derived by repeating the estimation of the same sample on 10 different occasions was $7 \cdot 5 \%$.

C4d concentrations in 20 healthy subjects and in $\mathbf{5 0}$ patients with rheumatoid arthritis are shown in fig 5. 


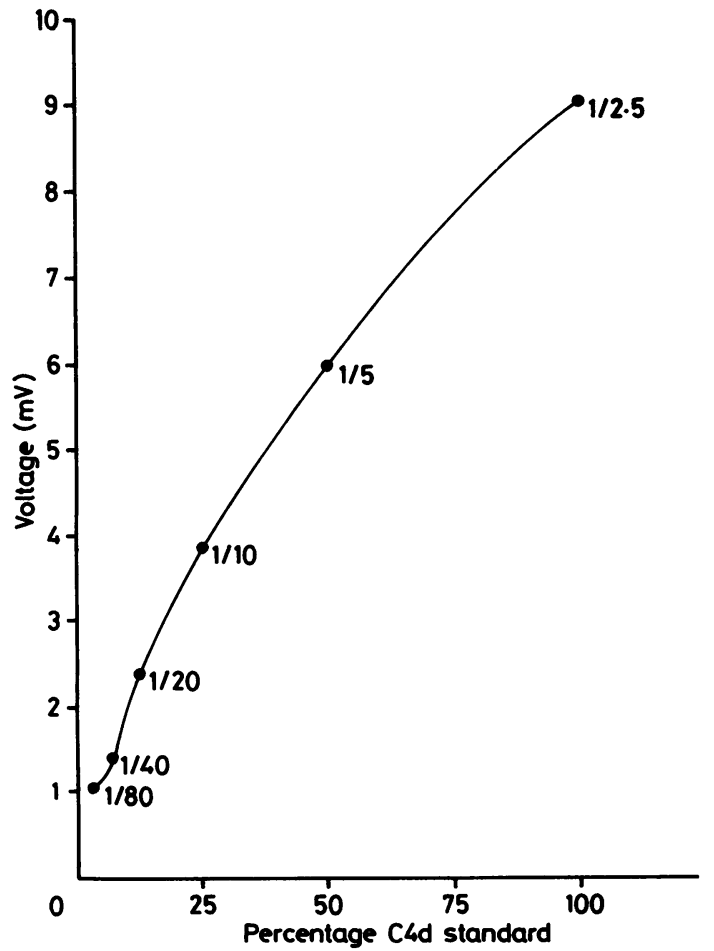

Fig 4 Reference curve derived from serial dilutions of supernatant of C4d standard from 1/2.5 to 1/80. Top dilution is given a value of $100 \%$.

C4d values are expressed as a percentage, the C4d standard being $100 \%$. Patients with rheumatoid arthritis presented with $\mathrm{C} 4 \mathrm{~d}$ values (mean $53.8 \%$, SD $23.7 \%$ ) significantly higher than those of controls $(21.7 \%$ SD $10.0 \%) ; p<0.001)$. Twenty nine of the 50 $(58 \%)$ patients had $\mathrm{C} 4 \mathrm{~d}$ concentrations above the upper limit of normal (mean control value $+2 \mathrm{SD}$ ).

\section{Discussion}

We established a new technique measuring $\mathrm{C} 4 \mathrm{~d}$ for the assessment of activation of the classical complement pathway. C4d values were found to be increased in most of the patients with rheumatoid arthritis, a typical immune complex disease,$^{15}$ in which the classical pathway is activated. ${ }^{910}$

Numerous assays aimed at assessing activation of the classical complement pathway have focused on the breakdown of $\mathrm{C4}$, a component exclusive to this pathway. Turnover studies based on the administration of radiolabelled $\mathrm{C} 4$, have provided evidence of hypercatabolism of the molecule in immune complex diseases, such as seropositive and seronegative arth- ritides. ${ }^{16}$ The invasive nature of the technique, however, precludes its routine clinical application.

Unequivocal evidence of classical pathway activation can be obtained through $\mathrm{C} 4$ breakdown products. C4 cleavage products have charge and molecular weight differences from intact $\mathrm{C} 4$ and they can therefore be identified by electrophoretic techniques, including immunoelectrophoresis, ${ }^{17}$ counter immunoelectrophoresis, ${ }^{18}$ and crossed immunoelectrophoresis. ${ }^{19}$ These techniques are insensitive and mainly provide qualitative results. Moreover, they are time consuming, laborious, and hardly suitable for analysis of large sample batches. Recently, rocket immunoelectrophoresis has been proposed for the quantitation of fragment $\mathrm{C} 4 \mathrm{~d} .{ }^{20} 21$ This assay also seems to be insensitive, failing to detect the concentrations of $\mathrm{C} 4 \mathrm{~d}$ present in normal subjects; and it is cumbersome, requiring photographic enlargement for interpretation of results.

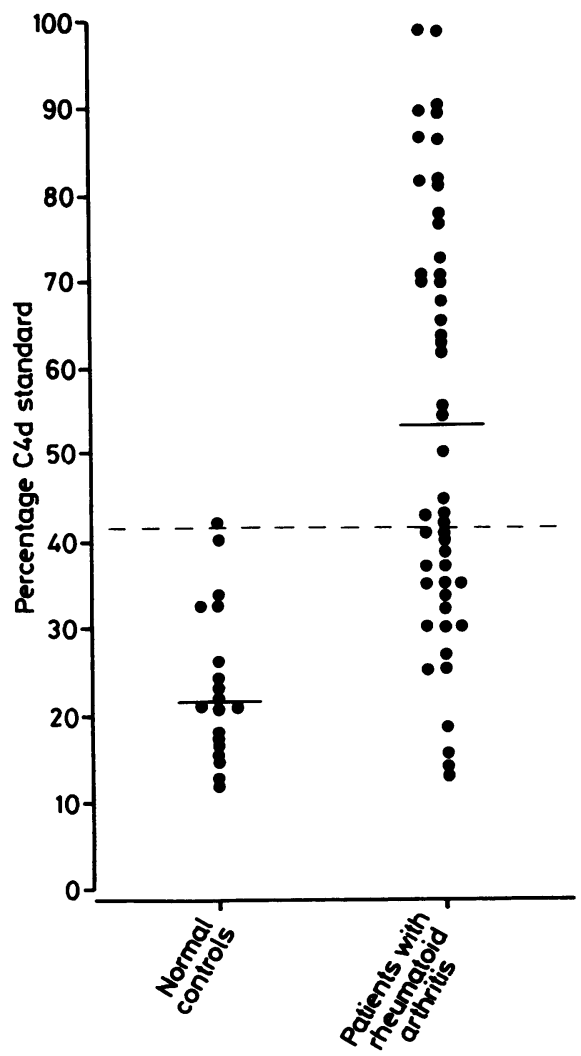

Fig 5 C4d in plasma of normal controls and patients with rheumatoid arthritis. Values are expressed as per cent of $C 4 d$ standard. Horizontal bars represent mean values. Dotted line indicates upper limit of normal (mean control value + 2SD). Patients with rheumatoid arthritis have significantly higher $C 4 d$ values than controls $(p<0.001)$. 
Products of the partial proteolysis of $\mathrm{C} 4$ can be identified by exploiting their solubility in PEG. High PEG concentrations precipitate intact complement factors and their heavier breakdown products, leaving lighter fragments in the supernatant where they can be quantitated. A radial immunodiffusion technique to measure PEG isolated C4d fragment has been reported. $^{12}$ This technique lacks sensitivity, is lengthy, and has never been reproduced because of the unavailability of commercial antisera specific for $\mathrm{C} 4 \mathrm{~d}$.

Lack of reactivity for $\mathrm{C} 4 \mathrm{~d}$ seems to be a common feature of commercial anti-C4 antisera, probably reflecting the weak immunogenicity of the $\mathrm{C} 4 \mathrm{~d}$ fragment. In this study only one of nine antisera tested could recognise $\mathrm{C} 4 \mathrm{~d}$. Using this antiserum we developed a laser nephelometric technique to measure C4d after its isolation in high concentration of PEG. This assay is sensitive, permitting the detection of small amounts of C4d present in normal subjects; precise, having low intra- and interassay coefficients of variation; rapid, providing results within four hours; and simple to perform. Furthermore, the steps following PEG separation of $\mathrm{C} 4 \mathrm{~d}$ can be fully automated.

The present study also shows that the measurement of $\mathrm{C} 4 \mathrm{~d}$ is of clinical value. The increased $\mathrm{C} 4 \mathrm{~d}$ concentrations found in most patients with rheumatoid arthritis provide clear evidence for classical complement pathway activation in this immune complex disease. Such activation could have been missed if intact $\mathrm{C} 4$ had been determined, as the concentrations are usually normal or increased in patients with rheumatoid arthritis, due to the behaviour of $\mathrm{C} 4$ as an acute phase reactant. ${ }^{422}$

Dr G Senaldi is supported by Fondazione Anna Villa Rusconi, Varese, Italy.

\section{References}

1 Lachmann PJ, Peters DK. Complement. In: Lachmann PJ, Peters DK, eds. Clinical aspects of immunology. Oxford: Blackwell Scientific Publications, 1982:18-49.

2 Whicher JT. The value of complement analysis in clinical chemistry. Clin Chem 1978;24:7-22.

3 Cooper NR, Nemerow GR, Meyers JT. Methods to detect and quantitate complement activation. Springer Semin Immunopathol 1983;6:173-94.

$4 \mathrm{Zvaifler}$ NJ. The immunopathology of joint inflammation in rheumatoid arthritis. Adv Immunol 1972;16:265-336.
5 Fielder AHL, Walport MJ, Batchelor JR, et al. Family study of the major histocompatibility complex in patients with systemic lupus erythematosus: importance of null alleles of C4A and C4B in determining disease susceptibility. Br Med J 1983;286:425-8.

6 Vergani D, Bevis L, Nasaruddin BA, Mieli-Vergani G, Tee DEH. Clinical application of a new laser nephelometric technique to measure complement activation. J Clin Pathol 1983;36:793-9.

7 Vergani D. Complement. Diabetic Medicine. 1986;3:306-11.

8 Fujita T, Gigli I, Nussenzweig V. Human C4-binding protein. II. role in proteolysis of $\mathrm{C} 4 \mathrm{~b}$ by $\mathrm{C} 3 \mathrm{~b}$-inactivator. $\mathrm{J}$ Exp Med 1978;148:1044.

9 Ruddy S. Plasma protein effectors of inflammation: complement. In: Kelly WN, Harris ED Jr, Ruddy S, Sledge CB, eds. Textbook of rheumatology. 2nd ed. Philadelphia: WB Saunders, 1985: 83-94.

10 Ruddy S, Austen KF. The complement system in rheumatoid arthritis. Arthritis Rheum 1970;13:713-23.

11 Valet G, Cooper NR. Isolation and characterisation of the proenzyme form of the Cls subunit of the first complement component. J Immunol 1974;112:339-50.

12 Perrin LH, Shiraishi S, Stroud RM, Lambert PH. Detection and quantitation in plasma and synovial fluid of a fragment of human $\mathrm{C} 4$ with alpha mobility generated during the activation of the complement pathway. J Immunol 1975;115:32-5.

13 Shiraishi S, Stroud R. Cleavage products of $\mathrm{C} 4 \mathrm{~b}$ produced by enzymes in human serum. Immunochemistry 1975;12:935-9.

14 Buffone GJ, Savory J, Hermans J. Evaluation of kinetic light scattering as an approach to the measurement of specific proteins with the centrifugal analyser. II. Theoretical considerations. Clin Chem 1975;21:1735-46.

15 Zvaifler NJ. Rheumatoid synovitis: an extravascular immune complex disease. Arthritis Rheum 1974;17:297-305.

16 Ruddy S, Carpenter CB, Chin KW, et al. Human complement metabolism: an analysis of 144 studies. 1975;54:165-78.

17 Budzko DB, Muller-Eberhard HJ. Cleavage of the fourth component of human complement (C4) by $\mathrm{Cl}$ esterase: isolation and characterization of the low molecular weight products. Immunochemistry 1970;7:227-34.

18 Arroyave CM, Tan EM. Detection of complement activation by counter immunoelectrophoresis (CIE). J Immunol Methods 1976;13:101-12.

19 Sjoholm AG, Laurell AB. Conversion of the fourth complement component studied by crossed immunoelectrophoresis. Clin Exp Immunol 1973;14:515-29.

20 Milgrom H, Curd JH, Kaplan RA, Muller-Eberhard, Vaughan H. Activation of the fourth component of complement (C4): assessment by rocket immunoelectrophoresis and correlation with the metabolsim of C4. J Immunol 1980;124:2780-5.

21 Nitsche JF, Tucker ES, Sugimoto S, Vaughan JH, Curd JG. Rocket immunoelectrophoresis of $\mathrm{C} 4$ and $\mathrm{C} 4 \mathrm{~d}$. A simple sensitive method for detecting complement activation in plasma. Am J Clin Pathol 1981;76:679-84.

22 Ruddy S, Gigli I, Austen KF. The complement system of man. (Fourth of four parts). N Engl J Med 1972;287:642-6.

Requests for reprints to: Dr D Vergani, Department of Immunology, King's College School of Medicine and Dentistry, Denmark Hill, London SE5 8RX, England. 